\title{
Estudantes de Letras e a leitura literária: novos leitores: entre o reconhecimento de leituras eruditas e a prática de leituras comuns
}

Maura Maria dos Santos * * (Faculdade de Educação
da UFMG/Doutoranda
em Educação)

\section{RESUMO}

Este estudo objetiva examinar a relação de estudantes de Letras com a leitura literária, adotando como referência um quadro teórico que se concentra na sociologia de Bourdieu e nas contribuições de trabalhos contemporâneos acerca da leitura. Baseamos nossas reflexões nos dados iniciais coletados junto a graduandos em Letras $(n=169)$ por meio de questionários que nos forneceram informações acerca de seu perfil socioeconômico, cultural, e de sua formação literária. Os resultados parciais apontam para duas direções: as preferências de leitura declaradas pelos pesquisados revelam relativa adesão à literatura canônica, mas não se restringem às obras de prestígio. A presença de práticas de leitura não controladas pela hierarquia cultural se mostra mais forte junto aos estudantes com maior capital cultural, cujos pais exercem ocupações típicas das classes dominantes e do sexo feminino. Embora essas conclusões possam ser parcialmente explicadas à luz do quadro teórico eleito, demandam novos estudos para sua melhor compreensão.

\section{PALAVRAS-CHAVE}

Formação de leitores. Curso de Letras. Práticas de leitura literária 


\section{INTRODUÇÃO}

A democratização do acesso da população à escola verificada no Brasil a partir da década de 1960 ocasionou a ampliação do debate sobre questões relacionadas com o ingresso de novos perfis de alunos nos diversos graus de ensino (ROJO, 2005, p.37). Nesse novo contexto, alguns cursos de nível superior menos demandados por alunos mais favorecidos socialmente passaram a ter de lidar com a presença de alunos oriundos de classes menos privilegiadas, cujas disposições e competências são percebidas como geralmente muito distanciadas daquelas que constituem o capital cultural responsável pelo sucesso escolar (cf. BOURDIEU, 2010).

As dificuldades advindas da distância cultural entre o novo alunado e suas experiências escolares tornam-se objeto de pesquisa em diversas áreas do conhecimento. Dentre as mais variadas questões focalizadas por estudiosos nesse novo cenário, como as que dizem respeito à relação entre sucesso escolar e origem social, destacamos aquelas ligadas à leitura, especialmente às relações entre práticas de leitura e propriedades sociais dos leitores.

Embora muitos estudiosos abordem essa problemática e os pontos de vista adotados focalizem aspectos diversos da leitura, interessa-nos 0 aprofundamento do conhecimento acerca da leitura literária daquele que consideramos um tipo especial de leitor: o estudante de Letras.

Apesar de ser pouco valorizado na hierarquia dos cursos de nível superior (BATISTA, 2007), esse curso supõe uma formação cultural intensamente associada às elites culturais, principalmente por exigir do estudante disposições como "a facilidade verbal e a cultura livre adquirida nas experiências extraescolares" (BOURDIEU, 2010, p.44). Os graduandos em Letras podem ser considerados como um tipo especial de receptores de obras literárias, pois fazem um curso que se caracteriza por visar mais diretamente à formação de leitores especializados. Por isso, suas leituras estão mais diretamente submetidas ao controle imposto pelos agentes autorizados e instituições envolvidas em sua formação leitora, acadêmica e profissional.

As mudanças já mencionadas no perfil dos estudantes a partir da crescente democratização do ensino no país e o discurso institucional que a acompanha revelam certo desconhecimento por parte de alguns professores do ensino superior da relação entre os novos graduandos com o conhecimento e a cultura legítima. 0 distanciamento desses alunos em relação ao perfil ideal do universitário que ainda predomina no imaginário dos docentes, a emergência 
de novos modos de produção e de recepção dos textos em decorrência do avanço tecnológico, os padrões contemporâneos de relação com a cultura legítima e de seu consumo (COULANGEON, 2004), bem como o paradoxo do modelo utilitarista que sustenta o pensamento dos bons alunos de meios privilegiados (CHARTIER, 2007) em oposição ao conservadorismo social de meios populares acerca da cultura são fatores que nos colocam diante da necessidade de aprofundarmos no conhecimento de questões como o posicionamento dos estudantes de Letras em relação à cultura literária, as estratégias e esforços que eles realizam para ajustar suas condutas aos ideais organizados em torno do campo acadêmico e literário, as relações que eles efetivamente estabelecem com o cânone literário e com as formas legítimas de sua recepção, as disposições e competências que desenvolvem durante o processo de formação no curso e, finalmente, como de fato leem os textos em suas práticas de leitura.

No intuito de aprofundar o conhecimento acerca da leitura literária do estudante de Letras, iniciamos nossa investigação mediante a aplicação de um questionário a 169 alunos de licenciatura em Letras de uma universidade federal de prestígio. ${ }^{1}$ Em decorrência da finalidade e da extensão concisa deste trabalho e, ainda, da amplitude dos dados coletados na primeira etapa de nossa pesquisa, somente alguns desses dados serão analisados.

Tendo em vista nosso pressuposto de que a leitura é um consumo cultural que se submete às mesmas normas válidas para outras práticas culturais pertencentes a diferentes domínios de prática da esfera social, consideramos o peso de sua apropriação desigual pelos membros pertencentes aos grupos sociais nos quais ela é considerada uma prática distintiva. Isso implica reconhecer a existência de práticas de leitura diversas realizadas por leitores cujos perfis podem ser delineados a partir de disposições individuais, culturais e sociais bastante heterogêneas.

O estudo das relações dos estudantes de Letras com a leitura permite, assim, depreender preferências e práticas diversificadas. É possível supor que a

O questionário aborda eixos temáticos que nos possibilitaram obter informações acerca do perfil socioeconômico e cultural dos graduandos em Letras, de sua trajetória escolar e no curso, da escolha e definição do currículo, da formação como leitor, das práticas de leitura e culturais, bem como do estilo de vida desses estudantes. Para a aplicação dos questionários foram selecionadas onze turmas do curso de Letras. A seleção desses sujeitos se deu pelo fato de estarem cursando, durante o primeiro semestre de 2011, disciplinas voltadas para o ensino, pois interessa à pesquisa explorar a temática da leitura tendo em vista a formação de professores. A maior parte da amostra cursava o nono período à época da coleta de dados. Trata-se, desse modo, de amostra casual. 
apropriação diferenciada do capital cultural que, juntamente com outros fatores, engendra essa diversificação, torna-se ainda mais decisiva entre os graduandos, na medida em que, nesse curso, o sucesso nos estudos literários está diretamente relacionado com os maiores rendimentos no mercado de bens simbólicos, bem como maior prestígio na ocupação docente. Como demonstram Silva e Batista (2011), pelo fato de dependerem de competências mais raras, as disciplinas literárias são as mais capazes de trazer benefícios simbólicos para os estudantes, razão pela qual, segundo os dados de sua pesquisa, são aqueles estudantes mais capitalizados culturalmente que direcionam seus investimentos para a área de literatura.

Dada a importância da cultura literária dos estudantes (suas preferências e conhecimentos) para a apropriação do capital literário que constitui uma das principais bases do curso de Letras e da identidade dos docentes de Língua Portuguesa, neste trabalho examinaremos sua distribuição na amostra, tendo em vista propriedades sociais relevantes, como capital cultural herdado e gênero. É importante destacar que, em função das características da amostra, a análise assumirá um cunho exploratório: seu principal objetivo será o de levantar hipóteses e direções de análise para desdobramentos futuros da pesquisa.

\section{PREFERÊNCIAS}

Estimulados a escolher, com base numa lista, seus gêneros de leitura preferidos (Tabela 1), os estudantes de Letras convergem na eleição da “literatura clássica" (27,2\%) e dos "romances contemporâneos" (22,5\%) como objeto de sua predileção. ${ }^{2}$ Convergem também naquilo que, em alguma medida, rejeitam (e cujos percentuais de escolha se aproximam de zero e por isso não foram discriminados na tabela): livros práticos (como os de bricolagem, culinária, decoração e jardinagem), livros sobre esportes, bem como obras de autoajuda.

Metade dos estudantes - se se somam as categorias "literatura clássica" e "romances contemporâneos" - declara, assim, preferências conformes à legitimidade literária e à instituição encarregada de inculcá-la. Essa

Embora a categoria "literatura clássica” pareça vaga ou ambígua na listagem, por meio da relação com os outros gêneros elencados, seu sentido adquire precisão: designa fundamentalmente as obras consagradas pela tradição literária; em oposição aos "romances contemporâneos", designa ainda as obras canônicas até meados do século XX (no questionário, para essa última categoria, se dava o exemplo de Clarice Lispector); em oposição, por fim, à categoria poesia, designa as obras em prosa. 
conformidade, porém, parece opor dois grupos: aqueles que se declaram mais dispostos a um consumo literário predominantemente conservador e ligado a uma tradição já firmada e difundida pela escola (os que preferem a "literatura clássica") e aqueles que se declaram mais propensos a um consumo literário que justamente rompe com essas formas tradicionais de produção e apropriação literárias e que caracterizam, em grande parte, o "romance contemporâneo", marcado pela experimentação e, em linhas gerais, pelo privilégio atribuído ao modo de representação sobre a representação mesma.

TABELA 1 - Distribuição das preferências por gêneros de leitura por propriedades sociais*

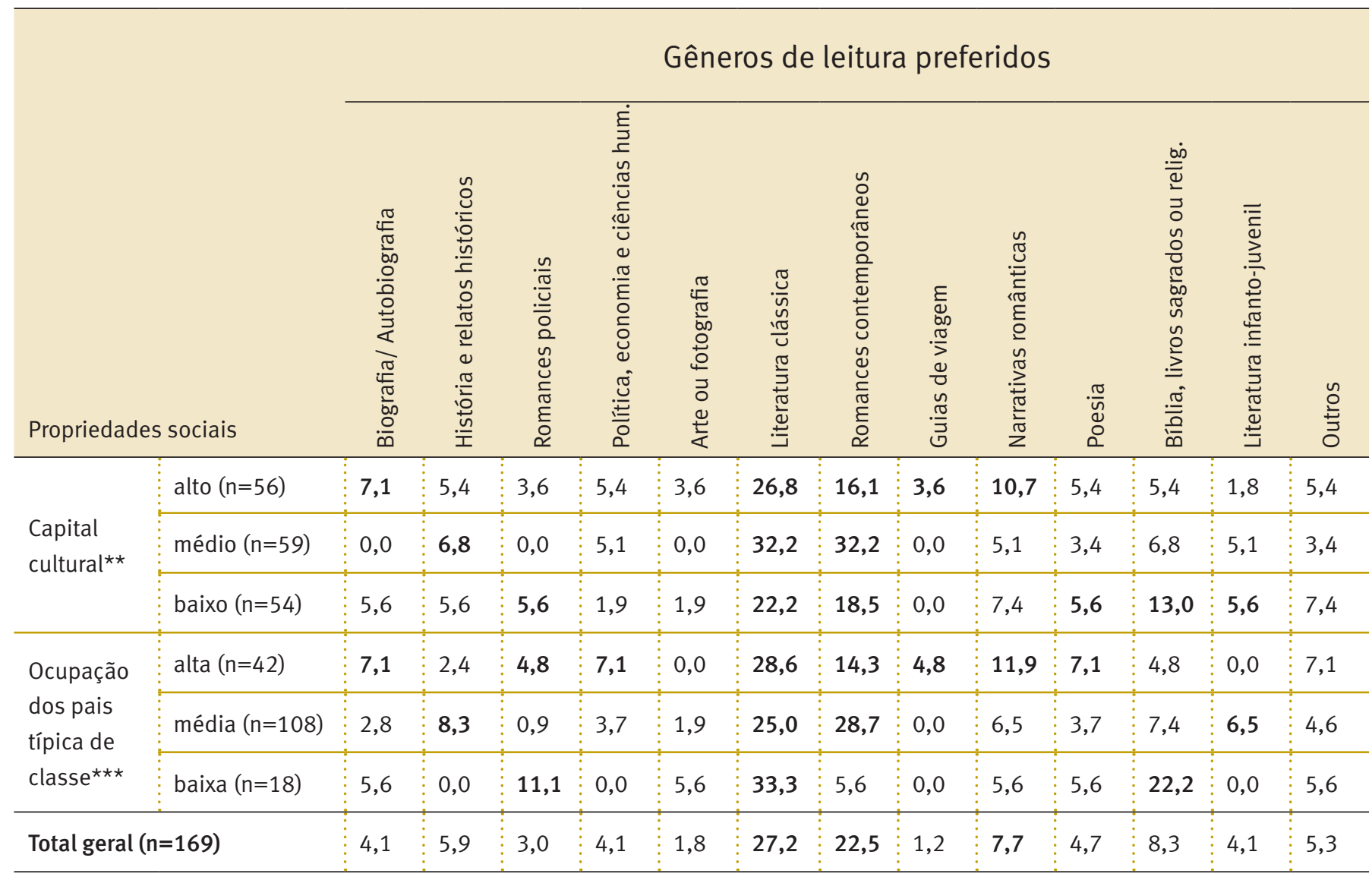

* Algumas somas não totalizam 100\% devido à ausência de respostas; pelo fato de terem sido inexpressivas, não foram incluídas na tabela.

${ }^{* \star}$ Capital cultural avaliado por meio do nível de escolaridade dos pais (ver, a respeito, BOURDIEU, 2008): alto, quando ambos os pais ou ao menos um deles possui escolaridade de nível superior completo ou acima; médio, se ambos os pais ou ao menos um deles possui nível médio completo ou superior incompleto; baixo, quando ambos os pais possuem nível de escolaridade inferior ao médio completo.

\begin{abstract}
*** Categorização feita de acordo com os agrupamentos adotados pela COPEVE (HTTP://www.copeve.ufv.br) cuja tabela serviu de orientação para os pesquisados responderem às questões do questionário relativas à ocupação dos pais: alto, se ambos os pais ou ao menos um deles possui ocupação pertencente aos grupos 1 e 2; médio, quando ambos os pais ou ao menos um deles possui ocupação pertencente aos grupos 3 e 4; baixo, se ambos os pais possuem ocupação pertencente ao grupos 5. Exemplos de ocupações dos grupos 1 e 2: banqueiro, profissional liberal de nível universitário, etc. Dos grupos 3 e 4: bancário, recepcionista, etc. Do grupo 5: operário (não-qualificado), servente.
\end{abstract}

Chama a atenção, porém, a dispersão das preferências por outros gêneros. Se, com certeza, a preferência por "poesia" - ainda que em percentuais discretos (4,7\%) possa se somar à por obras literárias legítimas, um pouco menos da metade dos estudantes parece se guiar por outros padrões em 
matéria de gostos de leitura.

Em se tratando ainda de leitura literária, cerca de 19\% se dividem entre gêneros literários tidos como "menores" na hierarquia cultural, ora fazendo sua predileção recair sobre "biografias e autobiografias" (4,1\%), ora sobre “romances policiais” (3\%) e sobre "literatura infanto-juvenil” $(4,1 \%)$, ora, especialmente, sobre as “narrativas românticas” (7,7\%).

Outra parcela dos estudantes dirige sua predileção para obras em que o estudo tende a assumir um papel central na leitura: cerca de 10\% preferem ler livros de "História" (5,9\%) e de "política, economia e ciências humanas" $(4,1 \%)$. Outro grupo, por fim, encontra suas leituras prediletas na "Bíblia e em livros sagrados ou religiosos" (8,3\%).

Em síntese, os dados parecem apontar para quatro padrões de predileção, de acordo com as declarações dadas pelos estudantes da amostra, que indicam, em ordem de importância, a preferência por:

I obras de literatura canônica ou legítima, principal padrão de predileção, apesar de opor, em seu interior, dois grupos de estudantes: de um lado, aqueles que declaram preferir obras baseadas na tradição literária e com mais firme presença na escola básica; de outro, aqueles que declaram uma adesão ao romance contemporâneo e, supostamente, a obras que buscam na inovação e na experimentação uma renovação da linguagem literária;

I obras tidas como gêneros "menores" na hierarquia social dos gêneros literários, como os romances policiais, as narrativas românticas e biografias e autobiografias, assim como a literatura infanto-juvenil;

III livros destinados ao estudo, na área de Ciências Humanas e Sociais;

IV Livros religiosos e sagrados.

\section{A DISTRIBUIÇÃO SOCIAL DAS PREFERÊNCIAS}

As regularidades apreendidas para o conjunto da amostra tendem a se alterar quando relacionadas ao capital cultural da família do estudante e à posição de sua família no espaço social, indicada - certamente de modo limitado - 
pela ocupação de seus pais (que, além de indicar prestígio, tende também a manifestar elementos do capital econômico e escolar).

A conclusão mais geral é a de que a adesão dos estudantes à literatura canônica (tradicional ou não) é mais forte junto aos estudantes cujo volume de capital cultural é médio, assim como é intermediária sua posição no espaço social. Se se somam os percentuais de preferência por "literatura clássica”, "romance contemporâneo" e "poesia”, os estudantes com volume médio de capital cultural alcançam uma concentração de $68 \%$, contra cerca de $50 \%$ entre os estudantes com volume alto de capital cultural herdado e aproximadamente $46 \%$ entre aqueles com baixo volume do mesmo capital. Regularidade semelhante se dá em se tratando da distribuição das preferências pela ocupação dos pais: os estudantes cujos pais exercem ocupações típicas de classe média tendem a declarar maior predileção pela literatura legítima (57,4\%), seguidos por aqueles cujos pais têm ocupações típicas de classes privilegiadas (50\%) e daqueles que exercem ocupações típicas das classes populares (44,5\%).

A menor adesão dos estudantes com menor volume de capital cultural e das camadas populares à literatura legítima e a um dos mais importantes valores que organizam o curso de Letras é passível de explicação pela sociologia bourdieusiana. Sendo produto da educação, o gosto supõe a internalização de um conjunto de conhecimentos e disposições que permitem a apropriação de uma produção cultural e as condições de socialização de indivíduos das camadas populares tendem a desfavorecer a aquisição desses conhecimentos e disposições (BOURDIEU, 2008).

O mesmo esquema explicativo permite compreender a forte adesão dos estudantes de estratos médios: sua posição intermediária na estrutura social favoreceria a construção de uma "boa vontade cultural”, de uma "docilidade cultural" que os tornaria sensíveis aos efeitos da legitimidade cultural e dotados de uma forte disposição para se empenhar na aquisição da cultura legítima (BOURDIEU, 2008). É um importante indicador desse esforço e das possibilidades explicativas desse quadro teórico o dado de que, dentre os três grupos e considerando as duas propriedades sociais retidas (capital cultural herdado e ocupação dos pais), é apenas entre os estudantes desses estratos que se encontram as mais altas preferências pelo "romance contemporâneo". Nesse caso, elas alcançam os mesmos patamares da predileção pela "literatura clássica” (32,2\% - tendo em vista o capital cultural) ou a suplantam (cerca de $29 \%$, contra $25 \%$ - tendo em vista a ocupação dos pais), o que não ocorre 
nos demais grupos de estudantes, em que a preferência pelas obras mais experimentais se dá sempre em percentuais expressivamente mais baixos.

O mesmo esquema explicativo, porém, apresenta certa limitação para compreender a menor adesão ou preferência dos estudantes com maior volume de capital cultural herdado pela literatura de prestígio, especialmente por aquela mais rara e distintiva e mais valorizada pela própria instituição literária, que é resumida pela categoria "romance contemporâneo", o que sugere que, nos desenvolvimentos posteriores da investigação, dedique-se atenção a esse ponto.

Como já se indicou, enquanto aproximadamente $68 \%$ dos estudantes com volume médio de capital cultural aderem à literatura legítima, apenas 50\% com alto capital cultural o fazem. Além disso, desses 50\%, apenas cerca de $16 \%$ declaram preferir "romances contemporâneos", justamente aqueles tipos de obras que mais dependem, para sua apropriação, do capital que, em regra, somente esses estudantes herdaram: dependem fortemente de um capital linguístico e de um conjunto de referências culturais não ensinadas diretamente pela escola. Mais ainda: os percentuais de preferências por uma suposta literatura "menor" ("literatura infanto-juvenil”, "narrativas românticas”, "romances policiais" e “biografias e autobiografias”), no caso desses estudantes, são superiores àqueles obtidos pelos romances "mais exigentes”, alcançando $23,2 \%$, em que se destaca o peso da predileção por “narrativas sentimentais", com percentuais de 10,7\%.

Essa regularidade poderia ser explicada, dentro do próprio quadro bourdieusiano, por um suposto esteticismo dos estudantes mais capitalizados culturalmente que thes permitiria "encontrar na mistura de gêneros e na subversão das hierarquias uma ocasião de manifestar a onipotência da disposição estética”, capaz de transformar quaisquer objetos em objetos de apreciação estética (BOURDIEU, 1983, p.111). 0 oposto se daria entre aqueles estudantes com volumes mais baixos de capital cultural, cuja escolha estaria condicionada ao modo tardio, metódico e esforçado de aquisição da cultura que os faria tender para escolhas "disparatadas" resultantes de um conflito entre "seus gostos de inclinação e seus gostos de vontade" (BOURDIEU, 1983, p.109). Os dados confirmam essa possibilidade de análise ao demonstrar, em relação a esses estudantes com menor capital cultural e cujos pais exercem ocupações típicas das classes populares, percentuais mais altos para a escolha de gêneros literários mais prestigiados $(44,5 \%)$ ao lado de percentuais expressivos de escolha de gêneros literários considerados menores (22,3\%) e de livros religiosos $(22,2 \%)$. 
Outra hipótese também familiar ao quadro bourdieusiano e que nos parece mais plausível para explicar o ecletismo dos estudantes com maior capital cultural diz respeito à possibilidade de esses estudantes pertencerem àquela fração das classes dominantes a que Bourdieu (2008) denomina "mundanos", isto é, àqueles grupos que, tendo adquirido muito precocemente de modo legítimo os modos legítimos de apropriação legítima das obras legítimas, possuem uma segurança e certeza de suas escolhas culturais que thes possibilitam viver num reino da liberdade e resistir a toda tentativa de sistematização e orientação explícitas de seu gosto: eles “formam o gosto".

De acordo com esse ponto de vista, a imersão precoce em um ambiente no qual a leitura tenha sido sempre considerada uma prática natural resulta em uma obtenção máxima do prazer de ler. Trata-se de uma forma de prazer maior e mais raro obtido por meio da liberdade e da frequência a um repertório cultural diversificado e amplo. Dessa maneira, esses herdeiros, ou indivíduos precocemente socializados na cultura dominante, tendo, por esse motivo, incorporado um alto capital cultural que resulta em certo domínio da linguagem e dos modos de expressão prestigiados socialmente se distinguem dos “pedantes" ou "doutos”, isto é, daqueles indivíduos que, não tendo as mesmas oportunidades dos "mundanos", devem todo o aprendizado ao sistema escolar e por esse motivo não dispõem da mesma liberdade de escolha dos primeiros (BOURDIEU, 2008).

Em decorrência de sua aprendizagem precoce e de sua familiaridade com a cultura dominante, os mundanos conferem às suas escolhas a liberdade do profundo conhecedor de uma espécie de "código dos códigos" que os tornam capazes de sustentar escolhas menos legítimas por meio de um "ecletismo erudito", que permite a eles desprezar os ditames dos supostos "pedantes" e das regras explícitas por eles ditadas. Como são, por esse motivo, mais imunes aos efeitos da legitimidade cultural das instituições, podem ousar, lançar regras (BOURDIEU, 2008).

Dessa maneira, é provável que, em nossa amostra, as proporções expressivas de estudantes com elevado capital cultural e oriundos de famílias cujos pais exercem uma ocupação de nível alto, e que escolheram gêneros literários menos prestigiados e, ao mesmo tempo, manifestam menor adesão à literatura contemporânea, estejam ligadas ao fato de pertencerem a esse grupo específico que exerce amplamente a liberdade de escolha.

Há também, por fim, uma hipótese ainda a ser considerada, fundamentada nos estudos de Coulangeon (2004) acerca das hierarquias culturais no 
mundo contemporâneo. Baseando-se em Richard Peterson (1992), o autor levanta a hipótese de que a adesão coerente à legitimidade cultural não é mais um fator distintivo entre as classes. Para ele, o que distingue as classes dominantes das populares é a variedade de práticas e gostos. Segundo esse modelo, os membros das classes superiores são caracterizados, sobretudo, pelo ecletismo de suas atitudes com relação à cultura (omnivorousness), enquanto os membros das classes populares manifestam hábitos e preferências exclusivos (univorousness).

Dessa maneira, enquanto a pertença às classes superiores se traduziria, segundo essa hipótese, por uma aptidão especial para a transgressão de fronteiras sociais e culturais entre os gêneros musicais, cinematográficos, literários, etc, como também entre as categorias de práticas (atividades culturais, no sentido estrito, mídia, esporte, bricolagem, jardinagem, turismo), a pertença às classes populares implicaria o encerramento em um repertório limitado de práticas e produtos de uma cultura de massa segmentada por um conjunto de critérios de geração ou etnia.

Portanto, apesar da aparente divergência entre essas abordagens, elas têm em comum o fato de admitirem a diversidade das práticas culturais das classes mais favorecidas, embora a expliquem de modos diferentes. Assim, em nossas análises futuras, buscaremos aprofundar a compreensão do fenômeno, seja empírica, seja teoricamente.

\section{A DISTRIBUIÇÃO SEXUAL DAS PREFERÊNCIAS}

A forte presença feminina em nossa amostra justifica que analisemos também as características desse grupo de leitoras. Apesar da presença masculina pouco expressiva na amostra, que limita a possibilidade de tirar conclusões mais sólidas, os dados parecem sugerir que são os estudantes do sexo masculino que fazem escolhas de leitura mais conformes às hierarquias culturais (Tabela 2) e que mais tendem a ler anualmente um maior número de livros não demandados pela Faculdade (Tabela 3). 
Tabela 2: Distribuição dos gêneros de livros preferidos por sexo

\begin{tabular}{|c|c|c|c|}
\hline \multirow{2}{*}{ Gêneros de livros } & \multicolumn{3}{|c|}{ Sexo } \\
\hline & Fem. & Masc. & Total \\
\hline \multicolumn{4}{|l|}{ Gêneros literários menores } \\
\hline Biografia e autobiografia & $5,4 \%$ & $0,0 \%$ & $4,1 \%$ \\
\hline Romances policiais & $2,3 \%$ & $5,1 \%$ & $3,0 \%$ \\
\hline Narrativas românticas & $10 \%$ & $0,0 \%$ & $7,7 \%$ \\
\hline Literatura infanto-juvenil & $3,8 \%$ & $5,1 \%$ & $4,1 \%$ \\
\hline Subtotais & $21,5 \%$ & $10,2 \%$ & $18,9 \%$ \\
\hline \multicolumn{4}{|l|}{ Gêneros para o estudo } \\
\hline História e relatos históricos & $7,7 \%$ & $0,0 \%$ & $5,9 \%$ \\
\hline Livros de política, economia ou de ciências humanas & $3,8 \%$ & $5,1 \%$ & $4,1 \%$ \\
\hline Subtotais & $11,5 \%$ & $5,1 \%$ & $10,0 \%$ \\
\hline \multicolumn{4}{|l|}{ Gêneros literários de prestígio } \\
\hline Poesia & $2,3 \%$ & $12,8 \%$ & $4,7 \%$ \\
\hline Literatura clássica & $25,4 \%$ & $33,3 \%$ & $27,2 \%$ \\
\hline Romances contemporâneos & $22,3 \%$ & $23,1 \%$ & $22,5 \%$ \\
\hline Subtotais & $50,0 \%$ & $69,2 \%$ & $54,4 \%$ \\
\hline \multicolumn{4}{|l|}{ Outros gêneros de livros } \\
\hline Bíblia, livros sagrados ou religiosos & $9,2 \%$ & $5,1 \%$ & $8,3 \%$ \\
\hline Livros de arte ou fotografia & $2,3 \%$ & $0,0 \%$ & $1,8 \%$ \\
\hline Guias de Viagem & $1,5 \%$ & $0,0 \%$ & $1,2 \%$ \\
\hline Outros & $3,8 \%$ & $10,0 \%$ & $5,3 \%$ \\
\hline Subtotais & $16,8 \%$ & $15,1 \%$ & $16,6 \%$ \\
\hline Total & $100 \%$ & $100 \%$ & $100 \%$ \\
\hline
\end{tabular}

Os estudantes declaram preferir - mais que as estudantes - ler poesia (12,8\% contra apenas 2,3\% das estudantes), ler "literatura clássica" (33,3\% contra $25,4 \%)$ e, ainda que mais discretamente, ler "romances contemporâneos" $(23,1 \%$ contra $22,3 \%)$. Ainda que metade das estudantes da amostra, mesmo que em percentuais menores que dos homens, prefira ler obras de prestígio, são elas, mais que os homens, que manifestam uma predileção pela leitura de obras literárias "menores" (21,5\% contra 10,2\%), especialmente por "biografias e autobiografias" (5,4\%) e, sobretudo, por "narrativas românticas" (10\%), gêneros pelos quais os homens manifestam clara recusa - nenhum escolheu um dos gêneros no questionário. Entre as obras "menores", os estudantes revelam predileção superior às mulheres apenas pelos "romances policiais" e, surpreendentemente - dada sua associação com a educação com a "literatura infanto-juvenil", com concentrações em torno de 5\%.

Assim, tanto homens quanto mulheres se mostram sensíveis às hierarquias literárias, os homens, porém, mais que as mulheres, uma vez que declaram maior predileção pelas obras “maiores" e menor apego às obras "menores”. 
Outros dois padrões são revelados pela Tabela 2: primeiro, que um percentual maior de estudantes do sexo feminino declara uma predileção por obras destinadas ao estudo $(11,5$ contra 5,1$)$; segundo, que são também elas que manifestam uma maior predileção pela leitura religiosa: 9,2\% contra 5,1\%.

Estudos sobre leitura e gênero mostram que jovens do sexo feminino desenvolveriam uma relação mais emocional com a leitura, enquanto a escolha da maioria de jovens do sexo masculino seria guiada por interesses profissionais e práticos (GARBE, 1993). As diferenças com relação à intensidade, às razões e às preferências de leitura de homens e de mulheres estariam associadas aos modos predominantes de socialização de ambos e se prolongariam na idade adulta. Para Horellou-Lafarge e Segré (2010), as moças leriam mais do que os rapazes e prefeririam os romances sentimentais, os romances psicológicos, os documentários e as experiências vividas, enquanto os rapazes manifestariam uma predileção por obras de ciências e de ficção científica, de história e romances policiais. Valendo-se de estudos de Parmentier (1986), as autoras (2010, p.109) observam que essas diferenças desapareceriam quando as mulheres chegam a um nível de instrução superior. Nesse nível de ensino "mulheres e homens têm, então, os mesmos gostos pela leitura de romances cultos, clássicos, ensaios”.

Embora os estudos de Garbe e de Horellou-Lafarge e Segré tenham sido realizados na França, observamos algumas semelhanças entre as questões suscitadas pelas autoras e alguns temas relacionados com a leitura no Brasil. Por esse motivo, acreditamos que os estudos citados podem nos auxiliar na reflexão acerca dos leitores e de suas práticas de leitura também no contexto brasileiro.

Assim, nossa análise dos primeiros dados da pesquisa corrobora, em parte, os estudos dessas autoras. Por um lado, o fato de os percentuais mais altos terem indicado a predominância da literatura clássica e dos romances contemporâneos na preferência tanto dos homens quanto das mulheres da amostra pode revelar a redução das prováveis diferenças entre o gosto masculino e feminino no nível superior de ensino, principalmente por se tratar de um curso de Letras.

Porém, as variações nos percentuais desses dois últimos parecem indicarmaior investimento dos homens na leitura dos gêneros diretamente relacionados com o interesse profissional nas áreas literárias. A diferença se torna mais expressiva se juntarmos a esses dois gêneros os percentuais indicados para a poesia, onde podemos verificar a opção de 69,2 \% dos homens contra 50\% 
das mulheres na soma dos percentuais das escolhas por esses três gêneros. A suposta preferência dos homens por romances policiais também pode ser ratificada pelos dados. 0 mesmo não ocorre com as obras de história, cujo percentual registrado foi de $0 \%$ por eles contra $7,7 \%$ entre elas, infirmando, em parte, o que dizem Horellou-Lafarge e Segré sobre as predisposições dos homens por esse gênero.

Ao contrário, a expressiva preferência de $10 \%$ das mulheres por narrativas românticas, terceiro maior percentual entre as pesquisadas e as diferenças entre os percentuais femininos e masculinos para biografia, Bíblia e demais livros sagrados parecem reforçar o envolvimento emocional do feminino com a leitura.

Garbe (1993) defende que, no estudo empírico do leitorado, a distinção entre leitores e não-leitores, fortes e fracos leitores, apreciadores de literatura geral ou de literatura especializada deve levar em conta as diferenças entre formação social masculina e feminina. Em nosso estudo incipiente essa diferença de comportamento verificada em relação às preferências de gêneros de livros pode ser verificada também em relação à frequência de leitura dos pesquisados, assim como a relação que eles estabelecem com as leituras mais diretamente controladas pelo curso e as leituras espontâneas ou cotidianas.

Como se poderá observar na Tabela 3, foi possível verificar que $56,8 \%$ dos homens leem anualmente mais de cinco livros, excetuando-se os livros obrigatórios do curso de Letras, enquanto no caso das mulheres esse percentual é de 42,9\%. O segundo maior percentual registrado é de 4 livros por ano para os homens $(21,6 \%)$ e de 3 para as mulheres $(16,7 \%)$, conforme apresenta a tabela abaixo:

TABELA 3: DISTRIBUI ÇÃO NO NÚMERO DE LIVROS LIDOS ANUALMENTE, EXCETUANDO OS LIVROS OBRIGATÓRIOS DO CURSO DE LETRAS POR SEXO

\begin{tabular}{lllllllllll}
\hline \multicolumn{1}{c}{ Sexo } & $\begin{array}{c}\text { Nenhum } \\
\text { livro }\end{array}$ & 1 livro & 2 livros & 3 livros & 4 livros & 5 livros & $\begin{array}{c}\text { Mais de } 5 \\
\text { livros }\end{array}$ & Total \\
\hline Feminino & $4,0 \%$ & $7,1 \%$ & $9,5 \%$ & $16,7 \%$ & $11,1 \%$ & $8,7 \%$ & $42,9 \%$ & $77,3 \%$ \\
\hline Masculino & $5,4 \%$ & $5,4 \%$ & $2,7 \%$ & $2,7 \%$ & $21,6 \%$ & $5,4 \%$ & $56,8 \%$ & $22,7 \%$ \\
\hline Total & $4,3 \%$ & $6,7 \%$ & $8,0 \%$ & $13,5 \%$ & $13,5 \%$ & $8,0 \%$ & $46,0 \%$ & $100 \%$ \\
\hline
\end{tabular}

A interpretação dos dados parece indicar maior investimento por parte dos homens nas leituras não-controladas pelo curso de Letras. Tal interpretação pode ser confirmada pelo dado de que, no momento da pesquisa, cerca 
de $61 \%$ dos homens contra $56 \%$ das mulheres estavam lendo algum livro relacionado ao seu gosto pessoal.

O inverso ocorre quando passamos a considerar as leituras obrigatórias do curso, ou seja, quando se trata de livros sugeridos pelos professores, a maioria das mulheres (60\%) contra 51\% dos homens declararam estar lendo algum livro indicado pelos professores do curso de Letras.

Essa constatação nos possibilita levantar a hipótese de que os pesquisados do sexo feminino tenderiam a investir mais nas leituras sugeridas pelos professores, enquanto os homens tenderiam a investir em leituras extraescolares, fato que pode estar relacionado com maior "docilidade cultural” em relação àquilo que é proposto pela universidade (BOURDIEU, 2008, p.78) por parte dos pesquisados do sexo feminino, o que, talvez, explique sua maior propensão - que os homens do curso - para as leituras voltadas para o estudo.

\section{CONSIDERAÇÕES FINAIS}

Este trabalho, cujo intuito foi refletir acerca das relações dos estudantes de Letras com a leitura, trouxe alguns dados que, ao afirmarem ou infirmarem os estudos teóricos e empíricos nos quais se fundamentou, permitiu a elaboração de hipóteses e o estabelecimento de direções de análise passíveis de nos auxiliar nos desdobramentos futuros de nossa pesquisa.

A síntese de algumas das propriedades sociais desses estudantes como capital cultural herdado e sexo nos forneceu uma referência a partir da qual analisamos suas preferências literárias em matéria de gênero de obras e de sua frequência de leitura de livros, buscando identificar alguns perfis de leitores pertencentes ao grupo estudado.

Embora o perfil predominante detectado na amostra tenha sido de estudantes do sexo feminino (76,9\%), detentores de capital cultural médio $(34,9 \%)$, pertencentes a famílias em que ao menos um dos pais exerce ocupação típica de classe média $(63,9 \%)$, foi possível apreender regularidades para os demais grupos da amostra definidos pelos mesmos critérios.

Esses dados parecem indicar que a adesão dos estudantes à literatura canônica (tradicional ou não) é mais forte junto àqueles que se caracterizam pela posse de um volume de capital cultural médio e por estarem em uma posição intermediária no espaço social. Enquanto mais da metade desses pesquisados se mostra mais sensível aos valores literários inculcados pela 
instituição escolar, outra parcela também expressiva manifesta preferências mais distanciadas desses valores.

Essa diversidade revelou outros perfis de leitores ou leitoras que nem sempre coincidiram totalmente com os pressupostos das teorias ou estudos que serviram de suporte para nossa análise. Dessa maneira, não foi possível explicar completamente algumas constatações como a menor adesão ou preferência dos estudantes com maior volume de capital cultural herdado pela literatura de prestígio representada em nosso estudo principalmente pelo romance contemporâneo, deixando-nos a alternativa de remeter este ponto para desenvolvimentos posteriores de nossa pesquisa.

Detectamos entre esses estudantes índices de preferências por uma suposta literatura "menor" superiores àqueles revelados pelos romances "mais exigentes". Além disso, um percentual expressivo de mulheres que declararam sua preferência por narrativas românticas nos remeteu ao quadro bourdieusiano no qual nos baseamos para propor algumas explicações possíveis. Porém, talvez ainda seja necessário complementarmos nossas hipóteses explicativas, colocando-nos a seguinte questão: que motivos levariam esses "herdeiros" a persistirem em práticas de leitura geralmente associadas a leitores e leitoras menos capitalizados culturalmente ou a leitores comuns?

Por fim, outro ponto que convém destacar refere-se à frequência de leitura dos estudantes. Enquanto os estudantes do sexo masculino parecem investir mais nas leituras não-controladas pelo curso, as estudantes do sexo feminino demonstram maior investimento nas leituras sugeridas pelos professores do curso. Embora tenhamos relacionado esse dado à suposta docilidade cultural por parte das mulheres em relação às normas da instituição escolar, ao confrontarmos essa hipótese com os resultados mencionados anteriormente acerca da preferência majoritariamente masculina por gêneros mais legítimos talvez tenhamos que concluir com uma última e importante indagação: qual é o impacto das diferenças de gênero em uma possível relativização da influência de um capital cultural previamente incorporado ou herdado na formação literária no curso de Letras? 


\section{Letters students and the reading of literature: new readers: between recognition of classical literature and the practice of everyday reading}

\section{ABSTRACT}

This study is aimed at examining the relationship between Letters students and the reading of literature, using a theoretical framework as a reference that is concentrated on the sociology of Bourdieu and on the contributions of contemporary work on reading. Our reflections are based on initial data collected from last year Letters students $(n=169)$ through questionnaires that provided us with information regarding their social and economic and cultural profiles and their literary background. The partial results point in two directions: the preferences for reading stated by those studied show a relative adhesion to canonical literature, yet they are not restricted to prestigious works. Reading practices that are not controlled by cultural hierarchy prove to have a stronger presence among students with greater cultural capital, whose parents held occupations typical of the dominant classes and of the female sex. Although these conclusions may be partially explained by the theoretical framework chosen, they require new studies for better comprehension.

\section{KEYWORDS:}

Reader education. Letters Course. Literature reading practices 
BATISTA, A. A. G. Professoras de Português, formação superior, matrimônio e leitura: um caso de estudo. In: PAIXÃO, Léa Pinheiro; ZAGO, Nadir (Org.). Sociologia da Educação: pesquisa e realidade brasileira. Rio de Janeiro: Vozes, 2007, p.79-109.

BOURDIEU, P. A distinção. Porto Alegre: Zouk; São Paulo: EDUSP, 2008. (1aa reimpressão).

BOURDIEU, P. A escola conservadora: as desigualdades frente à escola e à cultura. In: NOGUEIRA, Maria Alice; CATANI, Afrânio (Org.). Escritos de Educação. 11. ed. Petrópolis: Vozes, 2010. p. 39-64.

BOURDIEU, P. Gostos de classe e estilos de vida. In: ORTIZ, R. (Org.). PIERRE BOURDIEU. São Paulo: Ática, 1983.

CHARTIER, A. M. L'école et la lecture obligatoire. France: Ed. Retz, 2007.

COULANGEON, P. Classes sociales, pratiques culturelles et styles de vie: Le modèle de la distinction est-il (vraiment) obsolète ? In : Sociologie et sociétés. Les Presses de l'Université de Montréal. Vol. 36, n 1, 2004, p. 59-85 http:// id.erudit.org/iderudit/009582ar Acesso em 02/05/2010.

GARBE, C. Les femmes et la lecture. In: CHAUDRON, M.; SINGLY, F. (Org.). Identité, lecture, écriture. [S.I.] : Etudes et Recherche, Centre Georges Pompidou, 1993. HORELlOU-LAFARGE, C.; SEgRÉ, M. Sociologia da Leitura. Cotia, São Paulo: Ateliê Editorial, 2010.

Peterson, R. A. (1992), Understanding audience segmentation: From elite and mass to omnivore and univore. Poetics, $n^{\circ} 21$, p. 243-258.

ROJO, R. Programa 3. Livros em sala de aula: modo de usar. In: MATERIAIS Didáticos: escolha e uso: Boletim 14. Brasília: Ministério da Educação, 2005. p. 35-43.

SILVA, R. C. S; BATISTA, A. A. G. Flexibilização curricular e reprodução das desigualdades sociais: o caso da licenciatura em Letras da UFMG. Belo Horizonte: Faculdade de Educação da UFMG, 2011. Inédito.

Recebido em: NOVEMBRO de 2011

Aprovado em: MARÇO de 2012 